\title{
Safety and Analgesic Efficacy of Spinal Versus Caudal Block in Pediatric Infra-Umbilical Surgery
}

\author{
MAHMOUD A. ALI, M.D.; HALA S. ABD EL-GHAFFAR, M.D.; NAGWA M. IBRAHIM, M.D.; \\ ALAA M.A. ATTIA, M.D. and PETER S. ATALLAH, M.Sc.
}

The Department of Anesthesia, Faculty of Medicine, Assiut University, Assiut, Egypt

\begin{abstract}
Background: Neuraxial analgesia may improve postoperative outcomes for high-risk children who are susceptible to respiratory complications (e.g. post-operative apnea). The use of spinal anesthesia in infants and children requiring surgeries of sub-umbilical region is gaining considerable popularity worldwide. Caudal analgesia along with general anesthesia is a very popular regional technique for prolonged post-operative analgesia in different pediatric surgical procedures where the surgical site is sub-umbilical. Bupivacaine has been thoroughly studied, and a large global experience exists.

Aim of Study: Was to investigate the safety and analgesic efficacy of spinal versus caudal bupivacaine combined with sevoflurane anesthesia in children undergoing infra-umbilical surgeries.

Material and Methods: One hundred thirty patients of either sex aged between 2-7 years, (ASA I or II) were randomly assigned into two groups of 65 subjects each; Group A (caudal bupivaciane group) and Group B (spinal bupivaciane group). Group A received caudal isobaric bupivacaine, Group B received spinal hyper baric bupivacaine. Both after anesthesia induction and before surgery. Assessment parameters included; time to 1 st oral rescue analgesics, post-operative (FLACC scale), post-operative agitation, post-operative motor block component, haemodynamics, perioperative adverse effect.

Results: There were no significant differences between the two studied groups in the mean post-operative FLACC scores at any time except in the second post-operative hour in the spinal group $(0.84 \pm 0.07$ Vs. $1.13 \pm 0.08, p<0.01)$. The time to first request for rescue analgesia was significantly lower in the spinal group $(6.60 \pm 1.82$ Vs. $9.23 \pm 2.47, p<0.00)$ compared with the caudal group. There were no differences between the two studied groups in the total IV paracetamol consumption in the 1 st $24 \mathrm{~h}$ post-operatively ( $p=0.0674$ ). There were no significant differences in the mean post-operative modified bromage scale scores between the two studied groups at any time. The block was associated with few complications in both groups.
\end{abstract}

Correspondence to: Dr. Mahmoud A. Ali, The Department of Anesthesia, Faculty of Medicine, Assiut University, Assiut, Egypt
Conclusion: This study demonstrated that the spinal analgesia is fairly comparable to caudal analgesia in pediatric patients undergoing sub-umbilical surgeries. And we recommend the addition of an adjuvant to the intrathecal bupivacaine to prolong its analgesic effect making spinal analgesia a suitable alternative to caudal analgesia.

Key Words: Children - Post-operative pain - Analgesia Caudal-Spinal.

\section{Introduction}

PEDIATRIC acute pain services use techniques of concurrent or co-analgesia based on four classes of analgesics, namely local anesthetics, opioids, Non-Steroidal Anti-Inflammatory Drugs (NSAIDs), and acetaminophen (paracetamol). In particular, a local/regional analgesic technique should be used in all cases unless there is a specific contraindication and the opioid sparing effects of local anesthetics, NSAIDs, and acetaminophen (paracetamol) are useful.

Neuraxial analgesia may improve post-operative outcomes for high-risk children who are susceptible to respiratory complications (e.g. post-operative apnea) [1]. In this population, spinal anesthesia has been proposed as a means to reduce post-operative complications, [2] especially apnea and postoperative respiratory dysfunction, although this utility has been questioned.

Spinal anesthesia modifies the neuroendocrine stress response, ensures a more rapid recovery, and may shorten hospital stay with fewer opioidinduced side effects [3]. Recently, the use of spinal anesthesia in infants and children requiring surgeries of sub-umbilical region is gaining considerable popularity worldwide [4]. The ease of performance and the safety regarding cardio-respiratory functions makes spinal anesthesia as an alternative to 
general anesthesia in infants and children undergoing surgeries of sub umbilical regions [5].

Caudal analgesia along with general anesthesia is a very popular regional technique for prolonged post-operative analgesia in different pediatric surgical procedures where the surgical site is subumbilical. Caudal anesthetics usually provide analgesia for approximately 4-6 hours [6]. Bupivacaine has been thoroughly studied, and a large global experience exists. A concentration of $0.125 \%$ is sufficient to provide post-operative pain relief without significant motor blockade [7]. Slightly higher concentrations may be used for allowing very light general anesthesia during surgery [8-11]

\section{Material and Methods}

This prospective, randomized, double blind, comparative study was conducted in Assiut University Hospital after IRB approval from the Medical Ethic Committee, Faculty of Medicine, Assiut University, Assiut, Egypt. Trial registration was prospectively undertaken in clinical trial. gov (ID: NCT02988700). A written informed consent was obtained from the parental or guardian authorized representative before participation in the study. All collected data was confidential and was used for the purpose of scientific research only. Every research participant guardian had the complete right and freedom to withdraw at any time from the study with no negative consequences on the medical service provided to his or her child. One hundred thirty patients of either sex aged between 2-7 years, (ASA I or II) and scheduled for surgery below umbilicus under general anesthesia were included in this study. Patients with Allergic reaction to Local Anesthetics (LAs), local or systemic infection (risk of meningitis), coagulopathy, intracranial hypertension, hydrocephalus, intracranial hemorrhage, parental refusal, hypovolemia, spinal deformities, such as spina bifida or myelomeningocele, presence of a ventriculo-peritoneal shunt because of a risk of shunt infection or dural leak were excluded from the study.

Based on computerized generated randomization tables, patients were randomly assigned into two groups of 65 subjects each; Group A (caudal bupivaciane group) and Group B (spinal bupivaciane group). After anesthesia induction and before surgery, Group A received caudal isobaric bupivacaine and Group B received spinal hyper baric bupivacaine.

Children were assessed on the day before surgery and the parents were counseled about the procedure and post-operative pain assessments.
After taking detailed history, a thorough general and systematic examination was done and the weight of the patient was recorded.

After standard fasting times and without premedication, anesthesia was induced with sevoflurane $8 \%$ in $100 \%$ oxygen via Jackson Rees Breathing Circuit. Routine monitoring included; ECG, pulse oximetry, noninvasive blood pressure, endtidal carbon dioxide and temperature. An intravenous cannula was placed after induction of anesthesia and patients received intravenous Propofol $1-2 \mathrm{mg} / \mathrm{kg}$. An endotracheal tube of appropriate size or Laryngeal Mask Airway (LMA) was then inserted and anesthesia was maintained with 2-3\% Sevoflurane in $50 \%$ Oxygen/Air mixture. Patients also received intravenous paracetamol $15 \mathrm{mg} / \mathrm{kg}$. The mean arterial blood pressure and heart rate were maintained within $20 \%$ of baseline values by adjusting the sevoflurane concentration. Spontaneous breathing was maintained during surgery and an appropriate intravenous fluid infusion was administered at $10 \mathrm{ml} / \mathrm{kg} / \mathrm{h}$.

No sedatives or opioids were administered during operation. At the end of surgery, the LMA or endotracheal tube were removed, and the child was transferred to the Post-Anesthetic Care Unit (PACU) so long as there is no post-operative compromise in airway or hemodynamic instability, pain free and there was no post-operative vomiting.

The technique of caudal block: After induction of general anesthesia and before surgery, the patients were placed in the lateral decubitus position with knees drawn toward chest, the posterior superior iliac spines were palpated, and an equilateral triangle with the posterior superior iliac spines as the upper two corners was visualized. The lower apex of the triangle identifies the sacral ligament between the sacral cornua. While inserting the needle at $45^{\circ}$ to the skin in the midline, a distance "give" or "pop" was felt as the needle passes the sacral ligament into the caudal space. The needle was advanced only $1-2 \mathrm{~mm}$ further and the drug was injected after an appropriate test dose. Patients received caudal bupivacaine $0.25 \% 2.5 \mathrm{mg} / \mathrm{kg}$. Fifteen minutes after performing $\mathrm{CB}$, surgery was initiated. Cardio-acceleration changes (increasing heart rate and noninvasive mean arterial pressure $>15 \%$ in response to noxious surgical stimulation) and/or patient movement of his limbs were interpreted as insufficient analgesia. In such instances, CB was considered failed, then 1-2 $\mu \mathrm{g} / \mathrm{kg}$ IV fentanyl were administered, and the patient was excluded from the study. 
The technique of spinal block: After induction of general anesthesia and before surgery, spinal block was performed by elevating the head of the table 45 degrees while the puncture is made in the lateral position (this position could increase CSF pressure, widening the subarachnoid space) [12] An imaginary line connecting the top of the iliac crests crosses the spinal axis at the L3-L4 in older children [13]. Quincke needles 25G with a short bevel was used. The subarachnoid space is usually found $7-15 \mathrm{~mm}$ below the skin, but may be only $3 \mathrm{~mm}$ deep [14]. This space is very narrow (diameter of 6-8mm in term newborns) [15]. Patients received $0.25 \mathrm{mg} / \mathrm{kg}$ hyperbaric bupivacaine in a small syringe [16] plus $0.05-0.1 \mathrm{~mL}$ additional bupivacaine to compensate for the dead space of the spinal needle [17]. Otherwise, after completing the injection 0.2-0.3mL CSF was aspirated and re-injected [18].

Assessment parameters included; age, weight, sex ASA class, operation type and time, recovery time and time to 1 st oral intake were taken also, the heart rate, arterial blood pressure and peripheral arterial oxygen saturation. These parameters were recorded before the block and at 1, 3, 5, 15, 30, and $60 \mathrm{~min}$. after the block. Also mean arterial blood pressure was recorded before the block, and at $1,3,5,7,10,15,20$ and 30min. after the block. Post-operative pain was assessed using the Faces Legs Activity Cry Consolability (FLACC) scale. Postoperative pain intensity was evaluated on admition to PACU, and 2, 4, 6, 12 and 24h. postoperatively. Patients received $15 \mathrm{mg} / \mathrm{kg}$. i.v paracetamol rescue analgesia if requested and if FLACC scores were $\geq 4$ and the total consumption of postoperative rescue analgesics was recorded.

Post-operative motor block component was evaluated by the Modified Bromage scale; measured at awakening and at 30, 60, 90, 120 and 180 minutes after the last dose of local anesthetic. $(0=$ no motor block was present, $1=$ inability to stand unassisted, $2=$ ability to flex the ankle but not the knee, $3=$ complete motor block in a fully awake child).

Any perioperative adverse effect was treated and recorded such as hypotension, hypertension, tachycardia, bradycardia, arrhythmia, vomiting and no of attacks, urine retention, fever $>38.5$, wound infection or dehiscence or respiratory depression was treated and recorded.

\section{Statistical analysis:}

The primary endpoint of this study was the post-operative FLACC Scale scores. Based on previous studies [19], a target sample size was calculated. A power analysis estimated that a sample size of 60 patients in each group would have an $80 \%$ power at the 0.05 level of significance to detect a statistically significant difference between groups in the primary outcome parameter.

Distribution of baseline variables was assessed by the Shapiro-Wilk tests. Continuous data were reported as mean \pm SD and were analyzed using independent sample $t$-test or analysis of variance for multiple comparisons with least significant difference test for post hoc analysis. Categorical data were reported as percentages and were analyzed using the Chi square test or Fisher exact test as appropriate. Nonparametric data such as pain scores were analyzed using the Mann-Whitney Utest. A $p$-value of $<0.05$ was considered statistically significant. All statistical analyses were performed using IBM SPSS statistics Version 20 (SPSS Inc., Chicago, IL, USA).

\section{Results}

Patients' demographic and clinical characteristics:

There were no significant differences between groups in the demographic and clinical characteristics regarding age, ASA class, sex, weight (Table 1).

Table (1): Demographic data in studies group.

\begin{tabular}{llll}
\hline Item & $\begin{array}{c}\text { G1 "caudal } \\
\text { group" } \\
(\mathrm{n}=62)\end{array}$ & $\begin{array}{c}\text { G2 "spinal } \\
\text { group" } \\
(\mathrm{n}=63)\end{array}$ & $\begin{array}{c}p \text { - } \\
\text { value }\end{array}$ \\
\hline 1- Age (years) & $3.79 \pm 1.75$ & $3.50 \pm 1.33$ & $p=0.372 \mathrm{n} . \mathrm{s}$ \\
2- ASA Class: I/II & $61 / 1$ & $60 / 3$ & $p=0.863 \mathrm{n} . \mathrm{s}$ \\
3- Sex: & & & \\
$\quad$ Male & $49(79.6 \%)$ & $46(73.0 \%)$ & $p=0.282 \mathrm{n} . \mathrm{s}$ \\
$\quad$ Female & $13(21.0 \%)$ & $17(27.0 \%)$ & \\
4- Weight (kg) & $14.50 \pm 4.4$ & $13.76 \pm 3.58$ & $p=0.308 \mathrm{n} . \mathrm{s}$ \\
\hline
\end{tabular}

Data represented as mean $\pm \mathrm{SD}$, number and percentages.

ASA : American Society of Anesthesiologists

$p<0.05$ : Significance between groups.

\section{- Heart rate:}

Except for a higher mean heart rate at $60 \mathrm{~min}$. after the block in the spinal group $(119.75 \pm 21.31$ Vs. $100.57 \pm 15.38, p<0.006$ ), there were no significant differences between the two studied groups in the mean intraoperative heart rate either before or after the block or at any other time point in the study (Table 2).

\section{- The mean arterial blood pressure (MAP) :}

There were no significant differences between groups in the mean arterial blood pressure values at any time point in the study (Table 3 ). 
Table (2): Changes in the mean Heart Rate (HR) with time in the two studied groups.

\begin{tabular}{lccc}
\hline Item & $\begin{array}{c}\text { G1 "caudal } \\
\text { group" } \\
(\mathrm{n}=62)\end{array}$ & $\begin{array}{c}\mathrm{G} 2 \text { "spinal } \\
\text { group" } \\
(\mathrm{n}=63)\end{array}$ & $\begin{array}{c}p \text { - } \\
\text { value }\end{array}$ \\
\hline 1- Before block & $114.74 \pm 22.82$ & $115.00 \pm 13.11$ & $p=0.938 \mathrm{n} . \mathrm{s}$ \\
2- At 1 min & $118.92 \pm 20.45$ & $114.92 \pm 13.30$ & $p=0.197 \mathrm{n} . \mathrm{s}$ \\
3- At 3min & $117.10 \pm 20.59$ & $115.00 \pm 13.47$ & $p=0.501 \mathrm{n} . \mathrm{s}$ \\
4- At 5min & $119.87 \pm 20.28$ & $115.52 \pm 13.19$ & $p=0.157 \mathrm{n} . \mathrm{s}$ \\
5- At 15min & $117.60 \pm 20.91$ & $116.17 \pm 14.95$ & $p=0.665 \mathrm{~ns}$ \\
6- At 30min & $112.44 \pm 22.04$ & $113.75 \pm 20.24$ & $p=0.775 \mathrm{n} . \mathrm{s}$ \\
7- At 60min & $100.57 \pm 15.38$ & $119.75 \pm 21.31$ & $p<0.006^{*} *$ \\
8- At 90min & $104.00 \pm 0.00$ & $115.00 \pm 15.16$ & $p=0.361 \mathrm{n} . \mathrm{s}$ \\
9- At 120min & $104.01 \pm 0.12$ & $115.29 \pm 16.57$ & $p=0.901 \mathrm{n} . \mathrm{s}$ \\
\hline
\end{tabular}

Data represented as mean $\pm \mathrm{SD}$.

$p<0.05$ : Significance between groups.

Table (3): Changes in the mean arterial blood pressure (MAP) with time in the two studied groups.

\begin{tabular}{llcl}
\hline Item & $\begin{array}{c}\text { G1 "caudal } \\
\text { group" } \\
(\mathrm{n}=62)\end{array}$ & $\begin{array}{c}\mathrm{G} 2 \text { "spinal } \\
\text { group" } \\
(\mathrm{n}=63)\end{array}$ & $\begin{array}{c}p \text { - } \\
\text { value }\end{array}$ \\
\hline 1- Before block & $68.29 \pm 10.61$ & $64.36 \pm 5.27$ & $p=0.364 \mathrm{n} . \mathrm{s}$ \\
2- At 1 min & $65.19 \pm 7.50$ & $63.67 \pm 6.33$ & $p=0.322 \mathrm{n} . \mathrm{s}$ \\
3- At 3min & $61.66 \pm 10.42$ & $61.67 \pm 7.97$ & $p=0.994 \mathrm{n} . \mathrm{s}$ \\
4- At 5min & $59.74 \pm 13.86$ & $59.22 \pm 9.28$ & $p=0.829 \mathrm{n} . \mathrm{s}$ \\
5- At 7min & $54.85 \pm 15.25$ & $60.38 \pm 9.10$ & $p=0.072 \mathrm{n} . \mathrm{s}$ \\
6- At 10min & $55.15 \pm 14.58$ & $59.74 \pm 9.26$ & $p=0.125 \mathrm{n} . \mathrm{s}$ \\
7- At 15min & $55.97 \pm 14.051$ & $59.43 \pm 8.88$ & $p=0.156 \mathrm{n} . \mathrm{s}$ \\
8- At 20min & $54.18 \pm 15.58$ & $58.73 \pm 8.66$ & $p=0.129 \mathrm{n} . \mathrm{s}$ \\
9- At 30min & $56.94 \pm 18.70$ & $57.37 \pm 11.27$ & $p=0.156 \mathrm{n} . \mathrm{s}$ \\
\hline
\end{tabular}

Data represented as mean $\pm \mathrm{SD}$.

$p<0.05$ : Significance between groups.

\section{- FLACC scale:}

Except for a significantly lower mean FLACC scale score in the second post-operative hour in the spinal group $(0.84 \pm 0.07$ Vs. $1.13 \pm 0.08$, $p<0.01)$, there were no significant differences between the two studied groups in the mean postoperative FLACC scores at any time point in the study (Table 4).

Table (4): Assessment of FLACC scale in the two studied groups.

\begin{tabular}{|c|c|c|c|c|c|c|c|}
\hline Item & $\begin{array}{l}\text { G1 "caudal } \\
\text { group" } \\
(\mathrm{n}=62)\end{array}$ & $\begin{array}{l}\text { G2 "spinal } \\
\text { group" } \\
(\mathrm{n}=63)\end{array}$ & $\begin{array}{c}p- \\
\text { value }\end{array}$ & Item & $\begin{array}{l}\text { G1 "caudal } \\
\text { group" } \\
(\mathrm{n}=62)\end{array}$ & $\begin{array}{c}\text { G2 "spinal } \\
\text { group" } \\
(\mathrm{n}=63)\end{array}$ & $\begin{array}{c}p- \\
\text { value }\end{array}$ \\
\hline 1- $0 \mathrm{hr}$. & 0.0 & 0.0 & & 1- 0min. & $2.73 \pm 0.51$ & $2.81 \pm 0.39$ & $p=0.311 \mathrm{n} . \mathrm{s}$ \\
\hline 2- $2 \mathrm{hrs}$. & $1.13 \pm 0.08$ & $0.84 \pm 0.07$ & $p<0.01 *$ & 2- $30 \mathrm{~min}$. & $2.19 \pm 0.80$ & $2.40 \pm 0.49$ & $p=0.091 \mathrm{n} . \mathrm{s}$ \\
\hline 3- 4hrs. & $2.00 \pm 0.11$ & $2.19 \pm 0.12$ & $p=0.244 \mathrm{n} . \mathrm{s}$ & 3- $60 \mathrm{~min}$. & $1.76 \pm 0.84$ & $1.78 \pm 0.55$ & $p=0.877 \mathrm{n} . \mathrm{s}$ \\
\hline 4- 6hrs. & $3.03 \pm 0.12$ & $3.30 \pm 0.11$ & $p=0.103 \mathrm{n} . \mathrm{s}$ & 4- $90 \mathrm{~min}$. & $1.21 \pm 0.68$ & $1.33 \pm 0.47$ & $p=0.241 \mathrm{n} . \mathrm{s}$ \\
\hline 5- $12 \mathrm{hrs}$. & $2.13 \pm 0.14$ & $2.11 \pm 0.09$ & $p=0.917 \mathrm{n} . \mathrm{s}$ & 5- $120 \mathrm{~min}$. & $0.85 \pm 0.07$ & $0.75 \pm 0.09$ & $p=0.407 \mathrm{n} . \mathrm{s}$ \\
\hline 6- $24 \mathrm{hrs}$. & $1.00 \pm 0.15$ & $0.97 \pm 0.11$ & $p=0.868 \mathrm{n} . \mathrm{s}$ & 6- $180 \mathrm{~min}$. & $0.32 \pm 0.06$ & $0.27 \pm 0.05$ & $p=0.522 \mathrm{n} . \mathrm{s}$ \\
\hline
\end{tabular}

Data are represented as mean $\pm \mathrm{SE}$.

$p<0.05$ : Significance between groups at each respective time.

\section{-Post-operative analgesic consumption:}

All patients in the study requested for postoperative rescue analgesia. Fifty one Vs. 49 patients requested once for post-operative rescue analgesia in the caudal and spinal groups, respectively. Eleven patients in the caudal group Vs. 14 patients in the spinal group requested twice for post-operative rescue analgesia. No patient in the study requested for post-operative rescue analgesia more than twice. The time to first request for rescue analgesia was significantly lower in the spinal group $(6.60 \pm 1.82$ Vs. $9.23 \pm 2.47, p<0.00$ ), compared with the caudal group. There were no differences between the two studied groups in the total IV paracetamol consumption in the 1 st $24 \mathrm{~h}$ post-operatively ( $p=0.0674)$, (Table 5).

Table (5): Post-operative analgesic consumption in the two studied groups.

\begin{tabular}{|c|c|c|c|}
\hline Item & $\begin{array}{l}\text { G1 "caudal } \\
\text { group" } \\
(n=62)\end{array}$ & $\begin{array}{l}\text { G2 "spinal } \\
\text { group" } \\
(\mathrm{n}=63)\end{array}$ & $\begin{array}{c}p- \\
\text { value }\end{array}$ \\
\hline \multirow{2}{*}{\multicolumn{4}{|c|}{$\begin{array}{l}\text { Patients requests for } \\
\text { rescue analgesia in the } \\
\text { lst } 24 \text { host-operative: }\end{array}$}} \\
\hline & & & \\
\hline No request & 0 & 0 & $p=$ \\
\hline Once & 51 & 49 & $0.569 \mathrm{NS}$ \\
\hline Twice & 11 & 14 & \\
\hline$>2$ requests & 0 & 0 & \\
\hline Time to first request & $\begin{array}{l}9.23 \pm \\
2.47\end{array}$ & $\begin{array}{l}6.60 \pm \\
1.82\end{array}$ & $\begin{array}{l}p \\
<0.00 * * *\end{array}$ \\
\hline $\begin{array}{l}\text { Total consumption of } \\
\text { iv paracetamol (mg) in } \\
\text { the } 1 \text { st } 24 \mathrm{~h} \text { post- } \\
\text { operative }\end{array}$ & $\begin{array}{l}325.53 \pm \\
46.67\end{array}$ & $\begin{array}{l}366.25 \pm \\
49.53\end{array}$ & $\begin{array}{l}p \\
<0.0674\end{array}$ \\
\hline
\end{tabular}

\section{Modified bromage scale:}

There were no significant differences in the mean post-operative Modified Bromage Scale scores between the two studied groups at any time point in the study. No patient in the study showed a delayed motor weakness (Table 6).

Table (6): Post-operative modified bromage scale scores in the two studied groups.

Data are represented as mean $\pm \mathrm{SE}$.

$p<0.05$ : Significance between groups at each respective time. 


\section{Post-operative adverse events:}

- Four patients $(6.4 \%)$ in the caudal group versus $6(9.5 \%)$ in the spinal group complained from post-operative vomiting.

- Three patients in the spinal group (4.8\%) became feverish.

- There were no significant differences between groups in the overall incidence of post-operative adverse events $(p=0.352)$.

\section{Discussion}

In this study, we have demonstrated that the analgesic efficacy of spinal analgesia is fairly comparable to caudal analgesia in children undergone surgeries below the level of the umbilicus. The significant findings in this study were that the pain scores in $2 \mathrm{nd} h$ post-operatively were lower in the spinal group $(0.84 \pm 0.07$ Vs. $1.13 \pm 0.08, p$ $<0.01)$ and the time to first request to rescue postoperative analgesia was prolonged in the caudal group $(9.23 \pm 2.47$ Vs. $6.60 \pm 1.82 \mathrm{~h}, p<0.00)$. Otherwise, there were no significant differences between spinal and caudal analgesia in the post-operative pain scores in other time points, analgesic consumption either in agitation scores, Bramage Scale score or perioperative adverse effects.

In this study, we have demonstrated that the pain scores in $2 \mathrm{nd} \mathrm{h}$. post-operatively were lower in the spinal group $(0.84 \pm 0.07$ Vs. $1.13 \pm 0.08, p$ $<0.01)$ with no significant differences between groups in other time points in the study either in the post-operative consumption of rescue analgesia. Denoting that, the spinal analgesia can substitute caudal analgesia in pediatric surgeries below the umbilicus. The prolonged time to first request that was achieved with the caudal analgesia can be overcomed by adding an adjuvant to the spinal anesthetic to prolong its analgesic effect comparably.

In this study, we have demonstrated significantly lower mean agitation scores at $30 \mathrm{~min}$. and $45 \mathrm{~min}$. post-operatively in the spinal group with no significant differences in other time points. These results can be linked to the significantly lower pain scores we recorded in the spinal group in the 1 st h postoperatively adding an advantage of spinal analgesia over caudal analgesia in the effective control of pain in the early post-operative period. Because pain itself is the source of agitation, some authors reported a positive correlation between EA and pain [20].
XU et al., in their study have demonstrated that an increase in toe Perfusion Index (PI) is an early, reliable, and objective indicator of the successful onset of caudal anesthesia [21]. Conversely, failure to increase in PI might give the anesthesiologist an early warning of failure of adequate caudal block, which may help the anesthesiologist to optimize the management of anesthesia. In accordance, we demonstrated a significant difference between the two studied groups in the toe PI at 30min. after the block denoting that the onset of the caudal block was around that time. Which is indeed a long time when compared with spinal block, and in operations of moderate duration, the benefits of caudal analgesia are lost intraoperatively.

In this study we have recorded significantly lower mean systolic and diastolic blood pressure values at $60 \mathrm{~min} ., 90 \mathrm{~min}$. and $120 \mathrm{~min}$. after the block in the spinal group compared with the caudal group. The mean arterial pressure values in the spinal group were within the safe limits of autoregulation and showed no significant difference between caudal and spinal groups.

It has been stated that up to the age of 6-8 years even a high spinal [22] or epidural [23] block causes only minimal cardiovascular changes because of the relatively low basal sympathetic tone in this age range. Moderate blood pooling and vasodilatation in the lower part of the body [24] are counteracted by vasoconstriction in other areas of the body [25]. This phenomenon can be explained by a lower venous capacitance in the lower limbs, [26] less dependence of vasomotor tone in newborns, [27] and especially a compensatory decrease in vagal activity [28] following heart sympatholysis.

From the cardiovascular point of view, infants tolerate high spinal block better than adults. The young patients described by Williams and Abajian [29] and Finkel et al., [30] in whom high spinal anesthesia was induced purposely for cardiac surgery, showed a very stable cardiovascular status. However, individual patients, especially neonates and small infants with combined caudal and general anesthesia, can experience profound hypotension after a caudal block and our results disagree with these assumptions and further studies of large sample size are needed to confirm or declare these results.

In conclusion, this study demonstrated that the spinal analgesia is fairly comparable to caudal analgesia in pediatric patients undergoing subumbilical surgeries. And we recommend the addition of an adjuvant to the intrathecal bupivacaine 
to prolong its analgesic effect making spinal analgesia a suitable alternative to caudal analgesia.

Conflicts of interest: The authors declare that there is no conflict of interest.

Funding: The authors certify that no funding has been received for the conduct of this study.

\section{References}

1- CRAVEN P.D., BADAWI N., HENDERSON-SMART D.J., et al.: Regional (spinal, epidural, caudal) versus general anaesthesia in preterm infants undergoing inguinal herniorrhaphy in early infancy. Cochrane Database Syst. Rev., (3): CD003669, 2003.

2- TOBIAS J.D.: Spinal anaesthesia in infants and children. Paediatr. Anaesth., 10: 5-16, 2000.

3- SANG C. and BERDE C.: A multicenter study on safety and risk factors in pediatric regional analgesia. Anesthesiology, 81A: 1386, 1994.

4- JONES P., DALZIEL S.R., LAMDIN R. and MILESCHAN J.: Oral non-steroidal anti-inflammatory drugs versus other oral analgesic agents for acute soft tissue injury.

5- KOKKI H.: Spinal blocks. Paediatr. Anaesth., Jan., 22 (1): 56-64. Doi: 10.111 1/j. 1460-9592.201 1.03693.x. Epub. 2011 Sep. 7, 2012.

6- SHAH R.D. and SURESH S.: Applications of regional anaesthesia in paediatrics. Br. J. Anaesth., Dec., 111 Suppl 1: i114-24. Doi: 10.1093/bja/aet379, 2013.

7- WOLF A.R., VALLEY R.D., FEAR D.W., et al.: Bupivacaine for caudal analgesia in infants and children: The optimal effective concentration. Anesthesiology, 69: 1026, 1988.

8- GUNTER J.B., DUNN C.M., BENNIE J.B., et al.: Optimum concentration of bupivacaine for combined caudalgeneral anesthesia in children. Anesthesiology, 75: $57-$ 61, 1991.

9- PUNCUH F., LAMPUGNANI E. and KOKKI H.: Use of spinal anesthesia in paediatric patients: A single centre experience with 1132 cases. Paediatric Anaesth., 14: 5647, 2004.

10- KOKKI H., YLONEN P., LAISALMI M., HEIKKINEN M. and REINIKAINEN M.: Isobaric ropivcaine $5 \mathrm{mg} / \mathrm{ml}$ for spinal anesthesia in children. Anesth. Analg., 100: 6670, 2005.

11- KOKKI H., YLONEN P., HEIKKINEN M. and REINIKAINEN M.: Levobupivacaine for pediatric spinal anesthesia. Anesth. Analg., 98: 64-7, 2004.

12- APILIOGULLARI S., DUMAN A. and GOK F.: Do infants need higher intrathecal fentanyl doses than older children? Paediatr. Anaesth., 18: 1211-81, 2008.

13- TOBIAS J.D.: Spinal anaesthesia in infants and children. Paediatr. Anaesth., 10: 5-16, 2000.

14- NICKEL U.S., MEYER R.R. and BRAMBRINK A.M.: Spinal anesthesia in an extremely low birth weight infant. Paediatr. Anaesth., 15: 58-62, 2005.
15- DALENS B.J., ed. Regional anesthesia in infants, children and adolescents. London: Williams \& Wilkins, 261-73, 1995.

16- SURESH S. and WHEELER M.: Practical pediatric regional anesthesia. Anesthesiology Clin. N. Am., 20: 83113, 2005.

17- NICKEL U.S., MEYER R.R. and BRAMBRINK A.M.: Spinal anesthesia in an extremely low birth weight infant. Paediatr. Anaesth., 15: 58-62, 2005.

18- TOBIAS J.D.: Spinal anaesthesia in infants and children. Paediatr. Anaesth., 10: 5-16, 2000.

19- RAJAMANI A., KAMAT V., RAJAVEL V.P., et al.: A comparison of bilateral infraorbital nerve block with intravenous fentanyl for analgesia following cleft lip repair in children. Pediatr. Anaesth., 17: 133-9, 2007.

20- PATEL A., DAVIDSON M., TRAN M.C., et al.: Dexmedetomidine infusion for analgesia and prevention of emergence agitation in children with obstructive sleep apnea syndrome undergoing tonsillectomy and adenoidectomy. Anesth. Analg., 111: 1004-10, 2010.

21- XU Z., ZHANG J., SHEN H. and ZHENG J.: Assessment of Pulse Oximeter Perfusion Index in Pediatric Caudal Block under Basal Ketamine Anesthesia. The Scientific World Journal Volume, Article ID 183493, 6 pages, 2013.

22- DOHI S., NAITO H. and TAKAHASHI T.: Age-related changes in blood pressure and duration of motor block in spinal anesthesia. Anesthesiology, 50: 319-325, 1979.

23- DENG M., WANG X., WANG L., et al.: The hemodynamic effects of newborn caudal anesthesia assessed by transthoracic echocardiography: A randomized, doubleblind, controlled study. Pediatr. Anesth., 18: 1075-81, 2008.

24- HONG J.Y., AHN S. and KIL H.K.: Changes of dorsalis pedis artery flow pattern after caudal block in children: Observational study using a duplex sonography. Pediatr. Anesth., 21: 116-20, 2010.

25- PAYEN D., ECOFFEY C., CARLI P., et al.: Pulsed Doppler ascending aortic, carotid, brachial, and femoral artery blood flows during caudal anesthesia in infants. Anesthesiology, 67: 681-5, 1987.

26- DOHI S., NAITO H. and TAKAHASHI T.: Age-related changes in blood pressure and duration of motor block in spinal anesthesia. Anesthesiology, 50: 319-23, 1979.

27- DOHI S., NAITO H. and TAKAHASHI T.: Age-related changes in blood pressure and duration of motor block in spinal anesthesia. Anesthesiology, 50: 319-23, 1979.

28- OBERLANDER T.F., BERDE C.B., LAM K.H., et al.: Infants tolerate spinal anaesthesia with minimal overall autonomic changes analysis of heart rate variability in former premature infants undergoing hernia repair. Anaesthesia Analg., 80: 20-7, 1995.

29- WILLIAMS R.K. and ABAJIAN J.C.: High spinal anaesthesia for repair of patent ductus arteriosus in neonates. Paediatr. Anaesth., 7: 205-9, 1997.

30- FINKEL J.C., BOLTZ M.G. and CONRAN A.M.: Haemodynamic changes during high spinal anaesthesia in children having open-heart surgery. Paediatr. Anaesth., 13: 48-52, 2003. 


\section{سلامة وفاعلية مسكن للكتلة الشوكية مقابل الكتلة الزيليله

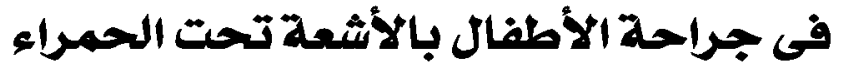

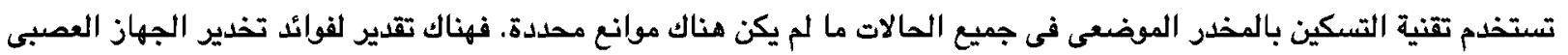

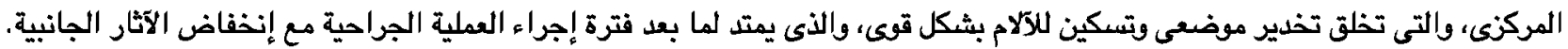

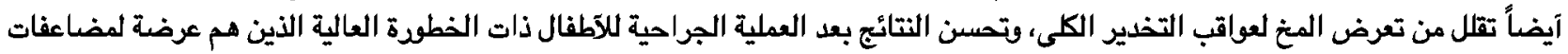

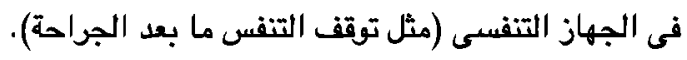

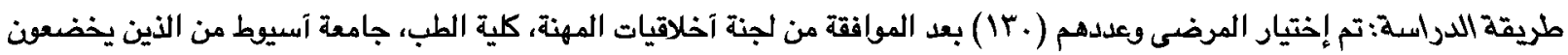

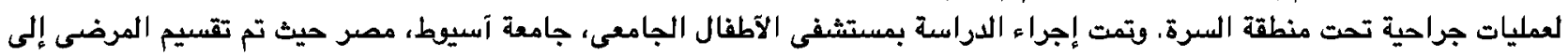
مجموعتين:

$$
\begin{aligned}
& \text { • الآولى : مجموعة التخدير النصفى بمادة الييوبيفيكين، بجرعة Yo ـ ملليجرام/كجم. }
\end{aligned}
$$

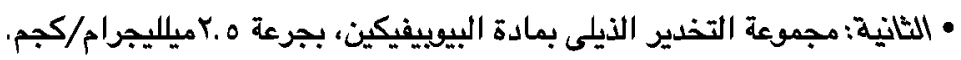

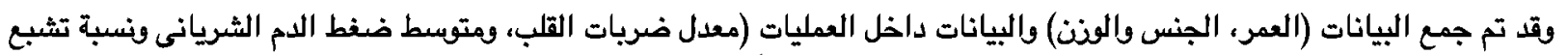

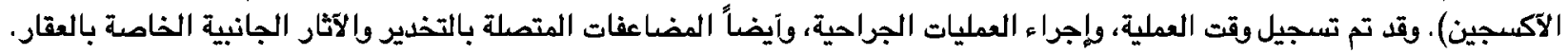

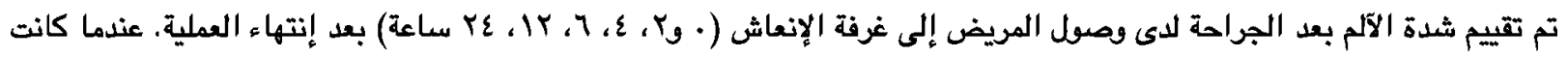

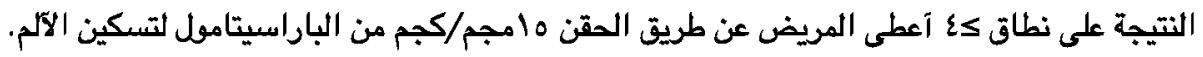

لا توجد فروق ذات دلالة إحصائية بين المجموعات فى الخصائص الايموغرافية المتعلقة بالعمر، والجنس، والوذن، سواء فى وقت التخدير،

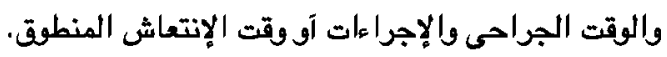

نتائج الدراسة: كان الوقت الآول لبداية إعطاء المسكن بعد العملية آتل بشكل ملحوظ فى مجموعة التخدير النصفى مقارنة مع مجموعة التخدير الذيلى.

آظهر المرضى فى المجموعة الثانية إنخفاض كبير جداً فى درجات الآلم بعد العملية الجراحية مقارنة مع المرضى في المجميوعة الآلولى.

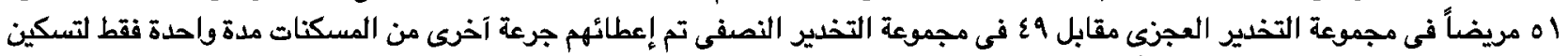

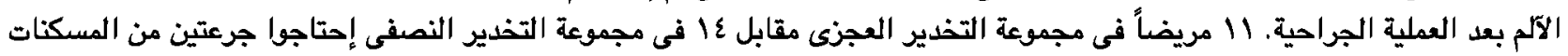

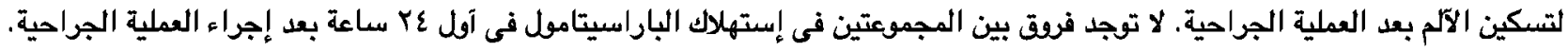

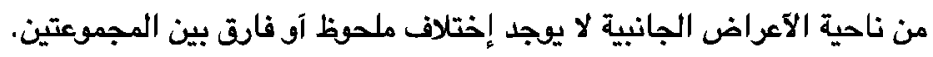

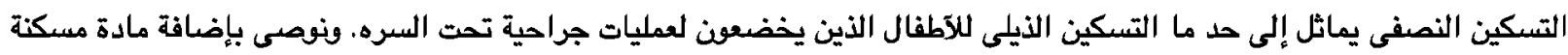

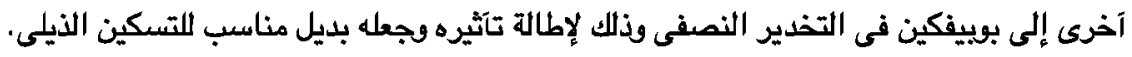

